\title{
Air Quality Modeling of Santhepet Street Canyon of Mysore City Using FLUENT
}

\author{
Lavanya G., Shamily B. M, \\ Shyamanth S. Kashyap \\ Dept. of Environmental Engineering, \\ VidyaVardhaka College of Engineering, \\ Mysore, Karnataka, India
}

\author{
Shilpa B. S. \\ Dept. of Environmental Engineering, \\ VidyaVardhaka College of Engineering \\ Mysore, Karnataka, India
}

\begin{abstract}
Automobile transport has become an inherent part of human life, and the adverse effect like air pollution is becoming more drastic. Vehicular traffic is leading to deterioration of air quality in the streets of Mysore city in recent years. It is very important to assess the impact of traffic related air pollution to take administrative decisions for improving air quality. In the present study, an attempt has been made to study the street canyon air quality by monitoring the concentration of pollutants like Suspended Particulate Matter (SPM), Sulfur dioxide $\left(\mathrm{SO}_{2}\right)$ and Nitrogen dioxide $\left(\mathrm{NO}_{2}\right)$ in Santhepet street canyon of Mysore city. Pollutants are monitored for 8 hours using instrument High Volume Air Sampler (HVAS) at two sampling stations in the canyon. During sampling period, the meteorological condition such as temperature, wind speed and humidity are found to be $33^{\circ} \mathrm{C}, 3-4 \mathrm{~km} / \mathrm{hr}$ and $50 \%$ respectively. The pollutants $\mathrm{SPM}, \mathrm{SO}_{2}$ and $\mathrm{NO}_{2}$ concentration at sampling station 1 are $943.89,15.73$ and $1319.57 \mu \mathrm{g} / \mathrm{m}^{3}$ and concentration of pollutants in sampling station 2 are $520.69,13.93$ and $350.87 \mu \mathrm{g} / \mathrm{m}^{3}$ respectively. Computational Fluid Dynamics (CFD) is a tool which assists in modeling the airflow and dispersion of pollutants among complex urban street canyons. FLUENT is the most widely used commercial CFD code for a range of flow applications. An attempt has been made to study the dispersion of the pollutants inside an urban street canyon using FLUENT.
\end{abstract}

\section{Keywords- Street canyon; Suspended Particulate Matter; Sulfur dioxide; Nitrogen dioxide; Modeling; FLUENT}

\section{INTRODUCTION}

Air quality in urban areas is getting deteriorated mainly due to the increased vehicular population in cities. Main traffic related pollutants include: Carbon monoxide (CO), Nitrogen oxides $\left(\mathrm{NO}_{\mathrm{x}}\right)$, Sulfur Dioxide $\left(\mathrm{SO}_{2}\right)$, hydrocarbons, and particulates. Poorly maintained vehicles gives rise to more pollution problems. These pollutants cause both acute and chronic effects on human health. $\mathrm{CO}$ reduces oxygen carrying capacity of blood; benzene pollutants can cause cancer whereas particulates and $\mathrm{SO}_{2}$ can cause respiratory diseases like asthma, bronchitis (UNEP, 2009).

In urban areas where population and traffic density are relatively high, human exposure to hazardous substances is significant. Due to this concern, the street canyons are considered as hot spots for air pollution problems. Irregular shape buildings contribute to enhance turbulence and vertical mixing in the atmosphere, while $W / H$ ratios (with $W$ the width and $H$ the height) of urban canyons affect street ventilation. More generally, buildings modify the flow field, influencing air exchanges and the dispersion of pollutants. Air quality dispersion models serve as a valuable tool for assessing the air quality against the National Ambient Air Quality Standards (NAAQS) and in decision making regarding the air pollution management. A variety of street canyon models are now available, starting from simple empirical models to complex Computational Fluid Dynamic (CFD) models. The pollutant concentration in street canyon mainly depends upon the traffic characteristics (type and number of vehicles), canyon geometry, urban background concentration, and meteorological parameters such as wind speed and wind direction (Vardoulakis et al., 2003).
Dispersion of pollutants originating from traffic is related to the geometry of the urban area and to the traffic conditions. Computational Fluid Dynamics (CFD) modeling is an important tool to understand and assess the airflow and dispersion of pollutants among complex urban geometries. Such model takes into account meteorological conditions, building designs and proximity of roadways to pollutant sources and enables more accurate predictions of pollutant dispersion. Furthermore, the limit of pollutant levels set by the World Health Organization has led to increased research activity to specify the influence of vehicular emissions on the air quality in urban street canyons. Urban street-canyons consist of uniform parallel building complexes on either side of the street and induce flow recirculation and/or stagnant conditions thus prohibiting the dispersion of pollutants away from inhabited areas.

The pollutants that are brought into the atmosphere by vehicular emission are dispersed (advected and diffused) over a wide range of horizontal length scales $(\mathrm{L})$. A distinction can be made between macro-scale dispersion ( $\mathrm{L}>1000 \mathrm{~km}$ ), meso-scale dispersion $(5 \mathrm{~km}<\mathrm{L}<1000 \mathrm{~km})$ and micro-scale dispersion $(\mathrm{L}<5 \mathrm{~km})$. The present study focuses on microscale dispersion in the vicinity of buildings within the street canyon. Important parameters for micro-scale dispersion are building geometry and environment topography, wind speed, wind direction, turbulence, stability, temperature, humidity and solar radiation.

Among the techniques commonly used to predict the dispersion of air pollutants in street canyon, Computational Fluid Dynamics (CFD) is widely used. Due to the turbulent nature of the wind flow around buildings, the accuracy of the CFD approach applied to urban dispersion problems is to a large extent determined by the performance of the turbulence 
approach and turbulence model used. Turbulence modeling approach used in the present study is Reynolds Averaged Navier-Stokes (RANS) with the standard k- $\varepsilon$ model (Brunekreef and Holgate, 2002). The objective of this research is intended to study the dispersion of the pollutants in busy area of an urban street canyon.

\section{STREET CANYON}

Street canyon is the deep, narrow, valley-like space above a street in a city, created by tall buildings on both sides as shown in Fig 2.1, which resemble the natural landform with the same name.

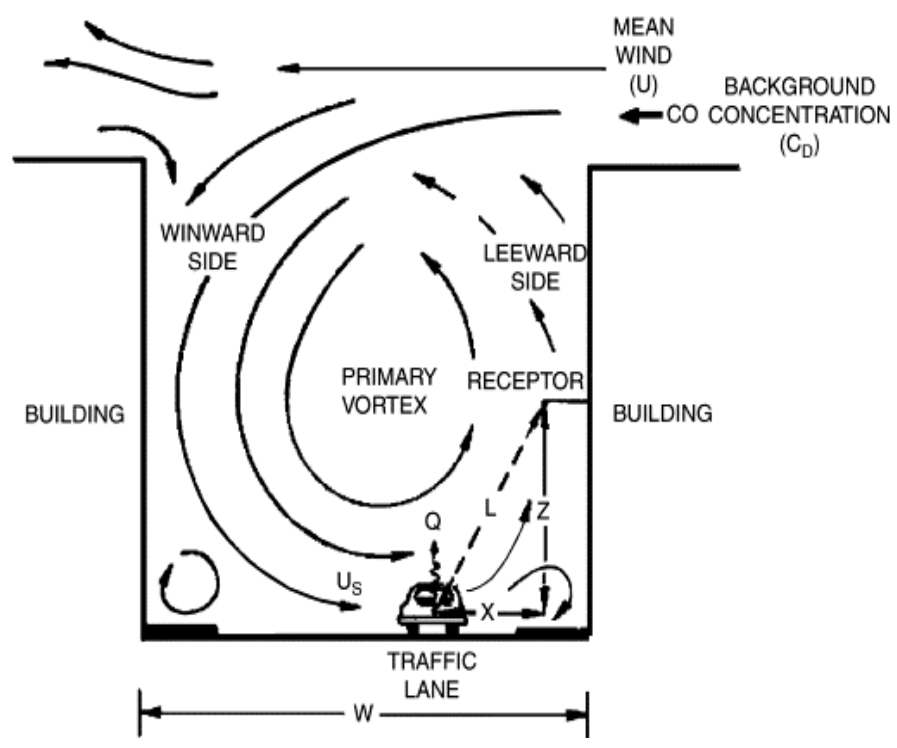

Fig 2.1 Schematic of the General Street Canyon

Street geometry includes the width and length of street, the width, height and length of the buildings which plays an important role in the dispersion of the pollutants inside the street canyon. Street canyons can be classified as Avenue canyon (i.e. canyons having aspect ratio i.e. H/W ratio less than 0.5 ) and Long canyons (i.e. L/H ratio >7)

\subsection{Street Canyon Models}

Street canyon models are very useful in traffic management, urban planning which are helpful for the design of streets, pollution forecasting, dispersion of pollutants within the street canyon and public health assessment. These models are STREET model, STREET Box model, Computational Fluid Dynamics (CFD) model (FLUENT, PHOENICS \& CHENSI), Urban Vegetative Canopy model (URVE) and Operational Street Pollution Model (OSPM). Among these CFD models, FLUENT software package is presently used to predict the dispersion of various pollutants inside the street canyon.

The software package FLUENT can be used to solve the Reynolds Stress Transport. This software package uses a standard k- $\varepsilon$ turbulence model to simulate the airflow and pollution transport in a 2-D and 3-D with different aspect ratio width/height $(\mathrm{w} / \mathrm{h})$. The air exchange rate of idealized street canyons and the complicated flow structures inside street canyons can be calculated using the FLUENT 6.3 code. Transport and dispersion modeling can be made by solving an Eulerian transport equation using the velocity and turbulence field found from the steady Reynolds-Averaged NavierStokes (RANS) solution (John Crowther et al., 2002).

\section{MATERIALS AND METHODOLOGY}

\subsection{Site Description}

Mysore city is located in south-western Karnataka at $12^{0} 30^{\prime} \mathrm{N}$ $76^{0} 13^{\prime}$ E. It has an elevation of 765 meters. The geographical area of the district is $128.42 \mathrm{Km}^{2}$. The Santhepet Street is one of the crowded streets in Mysore city which is located near the business area such as Devaraja Urs road and Krishna Raja market. This street is surrounded by many high rise buildings. As it is one of the main commercial areas in Mysore, large number of vehicles passes through this street and the location of Santhepet Street is shown in the Fig 3.1.

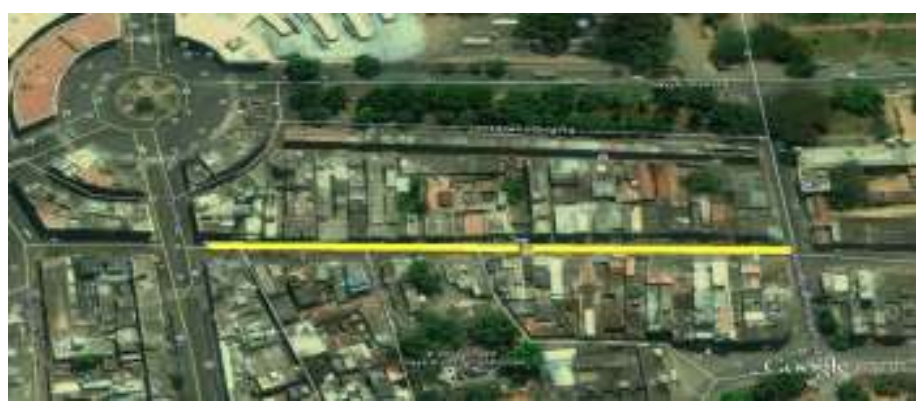

Fig 3.1 Location of the Santhepet Street, Mysore

\subsection{Canyon Geometry}

The emissions were measured over a length of $100 \mathrm{~m}$ and average road width is $6.6 \mathrm{~m}$.

Heights of buildings in the street canyon are as follows

- $\quad$ Buildings with 1 floor $=3.4 \mathrm{~m}$

- $\quad$ Buildings with 2 floor $=7 \mathrm{~m}$

- $\quad$ Buildings with 3 floor $=12 \mathrm{~m}$

Average building height in area is $8 \mathrm{~m}$. The aspect ratio of the canyon i.e. H/W Ratio is $1.21(8 / 6.6)$, the length to height ratio is also important in street canyon studies, and it was found to be $12.5(100 / 8)$. Such canyons are called as long canyons ( $\mathrm{L} / \mathrm{H}$ ratio $>7)$ and the schematic of the street geometry is as shown in the Fig 3.2 .

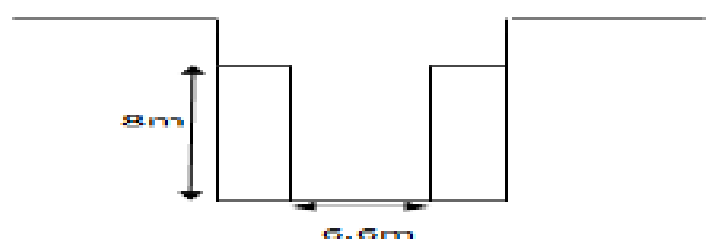

Fig 3.2 Schematic of the Street Geometry 


\subsection{Monitoring of Pollutants}

Two sampling stations were considered in the Santhepet street canyon as shown in the Fig 3.3 and sampling was carried for 3 days in each sampling station to determine the concentration of air pollutants such as $\mathrm{SPM}, \mathrm{SO}_{2}$ and $\mathrm{NO}_{2}$ for 8 hours using instrument High Volume Air Sampler (HVAS) as shown in the Fig 3.4 and Fig 3.5

The instrument HVAS works on the principle that Stoke's law, offers basic approach to collection of SPM using this technique. When operated in virtually quiescent of air, the geometry of HVAS employs the sloping roof of the shelter as a means for causing air entering the sampler under the caves of the roof to change the direction by at least $90^{\circ}$ before entering the horizontal filter. Only suspended particulate matter are collected on the filter paper. To determine the concentration of gaseous pollutants, $35 \mathrm{~mL}$ of absorbing solution is taken in impinger and the gaseous pollutants are collected through bubbling of air into the absorbing solution and the concentration of gaseous pollutants are determined.

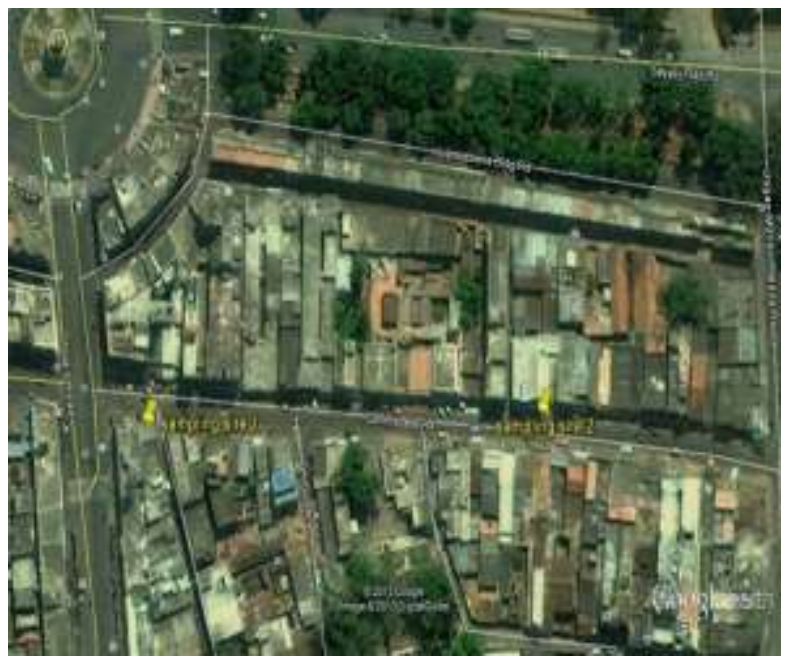

Fig 3.3 Location of the sampling points in Santhepet Street, Mysore [2]

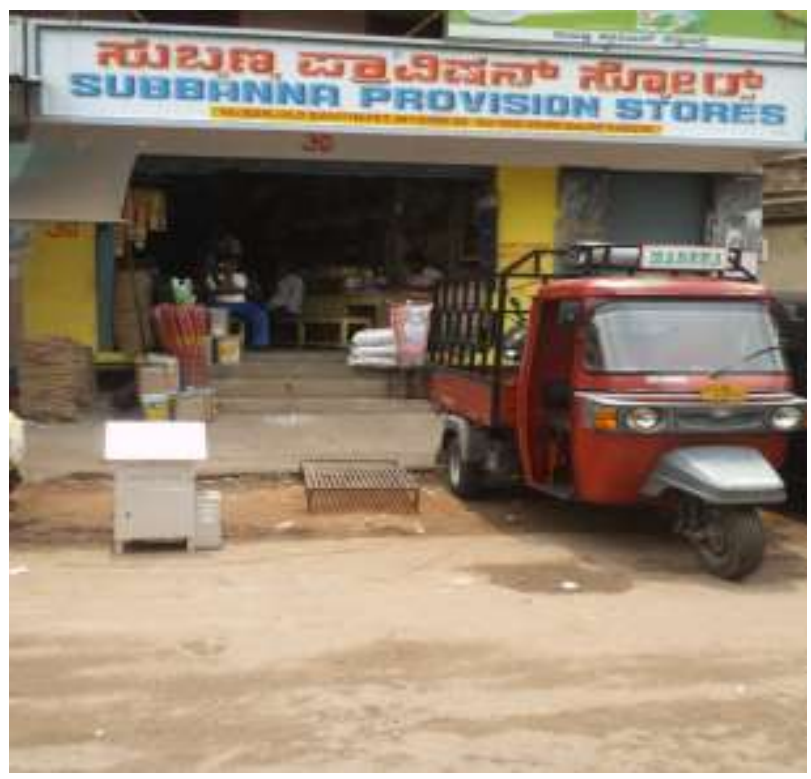

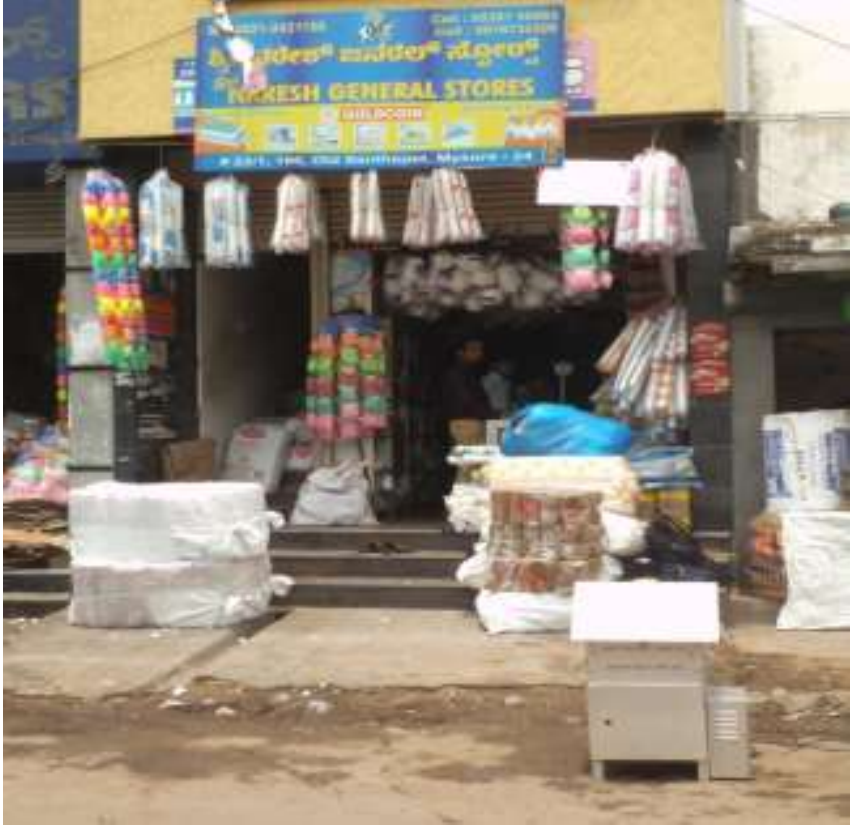

\section{Fig 3.5 Sampling at sampling point 2}

\subsection{Model Description}

FLUENT software is used to calculate air flow characteristics in different configuration of street canyons. FLUENT is a state-of-the-art computer program for modeling fluid flow in complex geometries. FLUENT provides complete mesh flexibility, including the ability to solve the flow problems using unstructured meshes that can be generated about complex geometries with relative ease. Supported mesh types include 2D triangular/ quadrilateral, 3D tetrahedral/ hexahedral/ pyramid/ wedge, and mixed (hybrid) meshes.

In this case, it is based on Reynolds-Averaged Navier-Stokes equations (RANS) and $k$ - $\epsilon$ turbulence model solve two equations, one of them for kinetic energy $(k)$ and other for dissipation $(\epsilon)$ (Chan, T. L. et al., 2002).

The software package contains three modules:

\section{FLUENT - CFD analysis module; version: 6.3 .26}

2. $\mathrm{T}$ grid - preprocessor; version: 4.0.16

3. Gambit - preprocessor; version: 2.3.16

The governing equations controlling the solution are partial differential equations for, mass, momentum and species transport of turbulent airflow which are written in Cartesian tensor notations in general form as follows

$$
\begin{aligned}
& \rho \frac{\partial u_{i}}{\partial t}+\rho \frac{\partial}{\partial x_{j}}\left(u_{j} u_{i}+\overline{u u_{j}^{\prime} u_{j}^{\prime}}\right)=-\frac{\partial P}{\partial x_{i}}+\frac{\partial}{\partial x_{j}}\left(\tau_{j}\right) \\
& \frac{\partial C^{\prime \prime}}{\partial t}+u_{j} \frac{\partial C^{\alpha}}{\partial x_{j}}=\frac{\partial}{\partial x_{j}}\left(\left(D^{=}+\frac{v_{t}}{S C_{i}}\right) \frac{\partial C^{\alpha}}{\partial x_{j}}\right)
\end{aligned}
$$

Fig 3.4 Sampling at sampling point 1 
Where $u_{i}$ and $P$ are the fluid mean velocity and pressure, $\hat{u}_{i}$ is the fluctuating velocity, $\rho$ represents fluid density, and $v$ is the kinematics viscosity. In Equation (2) $C^{\alpha}$ is the concentration of pollutant species $\alpha$ and $D^{\alpha}$ is its diffusivity, $v_{t}$ is the turbulence eddy Viscosity and $\mathrm{Sc}_{\mathrm{t}}$ is turbulence Schmidt number.

The term $\overline{u_{i}^{\prime} u_{j}^{\prime}}$ in Equation (1) is the time-averaged rate of momentum transfer due to turbulence. The turbulent kinetic energy $\mathrm{k}$ is defined as half the trace of the Reynolds stress tensor such that

$$
k=\frac{1}{2} \sqrt{\overline{u_{i} u_{j}}}
$$

The Navier-Stokes equations represent the governing equations for momentum conservation of a Newtonian fluid and it is given as

$$
\rho\left(\frac{\partial u_{j}}{\partial t}+u_{j} \frac{\partial u_{i}}{\partial x_{j}}\right)=\rho f_{i}-\frac{\partial P}{\partial x_{i}}+\mu\left(\frac{\partial^{2} u_{i}}{\partial x_{j}^{2}}+\frac{1}{3} \frac{\partial^{2} u u_{j}}{\partial x_{j} \partial x_{j}}\right)
$$

Where $u_{i}, P, \rho, \mu, f_{i}, t, x_{i}$ represent the fluid velocity, pressure field, density, viscosity, body forces, time and spatial dimensions respectively.

Model of street canyon constucted using GAMBIT preprosser is as shown in the Fig 3.6

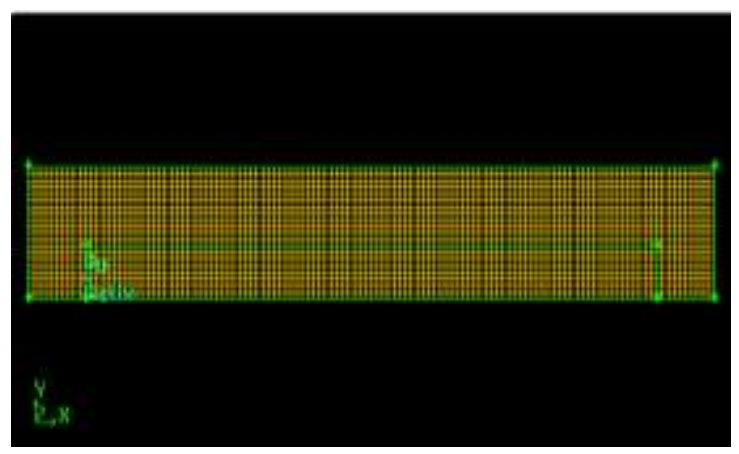

Fig.3.6 Model of street canyon constructed using GAMBIT

\section{RESULTS}

Vehicular count and concentration of the pollutants such as $\mathrm{SPM}, \mathrm{SO}_{2}$ and $\mathrm{NO}_{2}$ when monitored in the street canyon by adjusting the flow rate as $1 \mathrm{lps}$, at 2 different sampling points for 8 hours, are shown in the Fig 4.1 to Fig 4.4

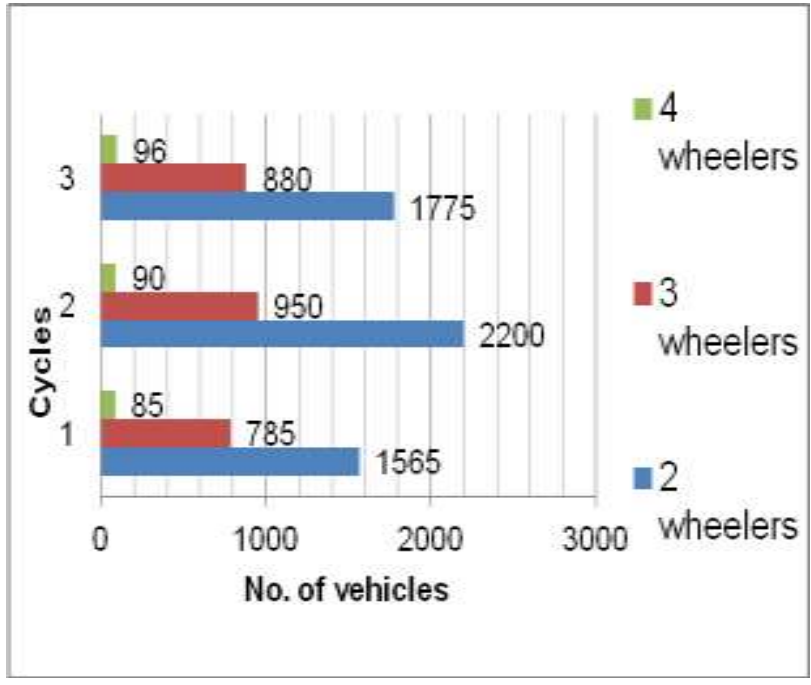

Fig 4.1 Traffic Data During Study Period at Sampling Point 1

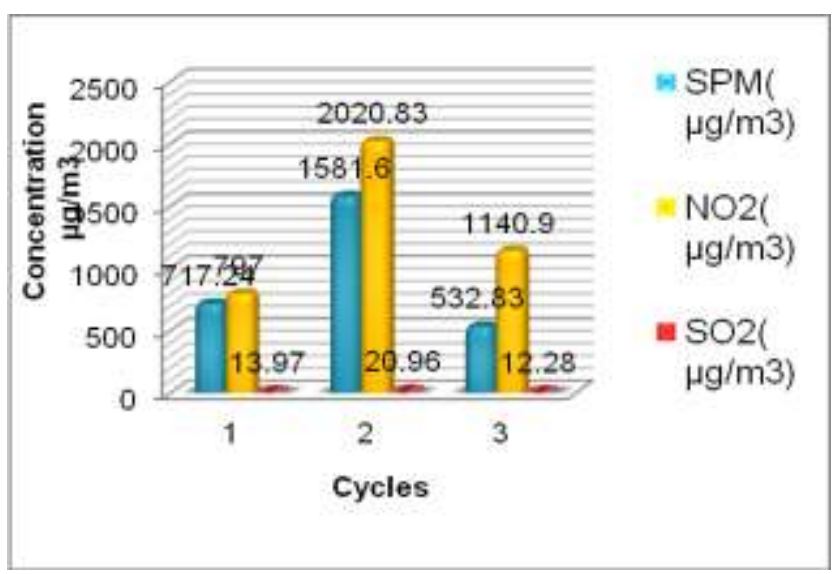

Fig 4.2 Pollutants Concentration at Sampling Point 1

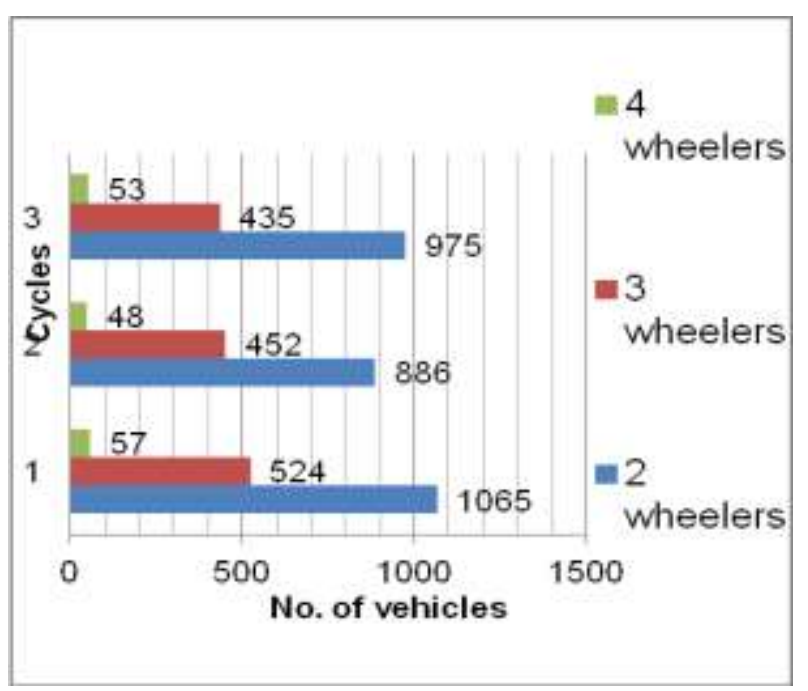

Fig 4.3 Traffic Data During Study Period at Sampling Point 2 


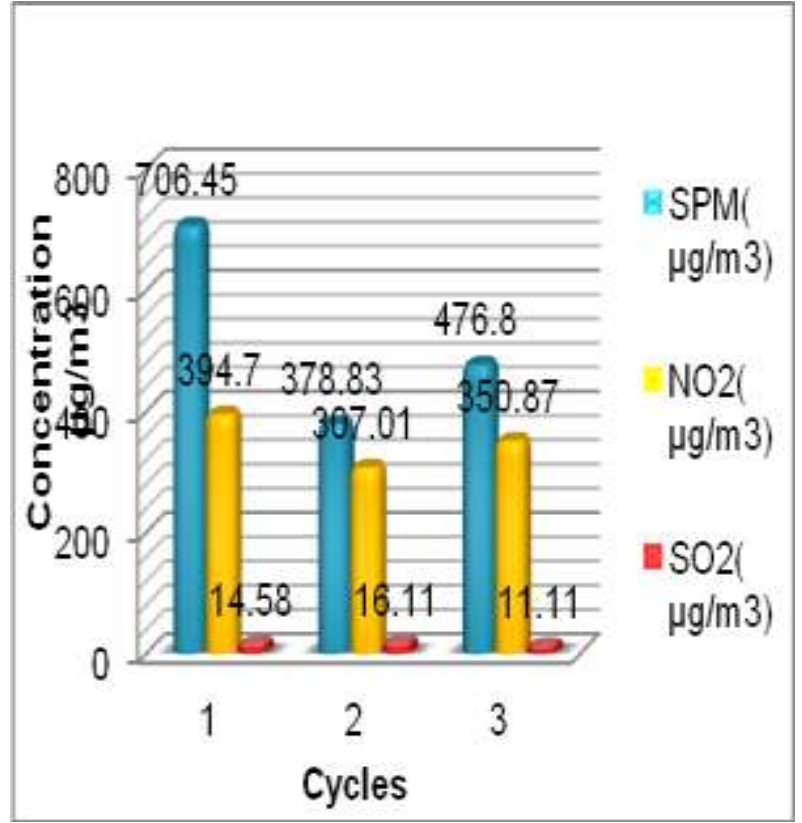

Fig 4.4 Pollutants Concentration at Sampling Point 2

The concentration of SPM was found to be more during second cycle i.e., $1581.6 \mu \mathrm{g} / \mathrm{m}^{3}$ in sampling point1 due to more vehicular traffic, whereas the SPM concentration was relatively less during first and third cycle due to decreased vehicular flow. In sampling point 2, the concentration of SPM was more during the first cycle i.e., $706.456 \mu \mathrm{g} / \mathrm{m}^{3}$ due to more vehicular traffic, whereas the concentration of SPM in the second and third cycle was relatively less due to decreased traffic.

In sampling point 1 , the concentration of $\mathrm{NO}_{2}$ determined was more during the second cycle due to more vehicular traffic data which releases more concentration of $\mathrm{NO}_{2}$ i.e., $2020.836 \mu \mathrm{g} / \mathrm{m}^{3}$ and the concentration of $\mathrm{NO}_{2}$ during first and third cycle was found to be relatively less due to decreased vehicular traffic. In sampling point 2 , the concentration of $\mathrm{NO}_{2}$ was more during the first cycle i.e., $394.76 \mu \mathrm{g} / \mathrm{m}^{3}$ due to more vehicular traffic and it was found to be relatively less during second and third cycle due to the decreased vehicular traffic.

The concentration of $\mathrm{SO}_{2}$ in both sampling point 1 and sampling point 2 during all 3 cycles was found to be very less. The maximum and minimum concentration of $\mathrm{SO}_{2}$ was found to be $15.73 \mu \mathrm{g} / \mathrm{m}^{3}$ and $13.93 \mu \mathrm{g} / \mathrm{m}^{3}$ in sampling point 1 and sampling point 2 . This is due to the fact that the exhaust emission from the vehicles does not contain more concentration of $\mathrm{SO} 2$.

After constructing the street canyon model in GAMBIT preprocessor and simulating in FLUENT code, following results were obtained. The pressure and the velocity profile are shown in Fig 4.5 and Fig 4.6

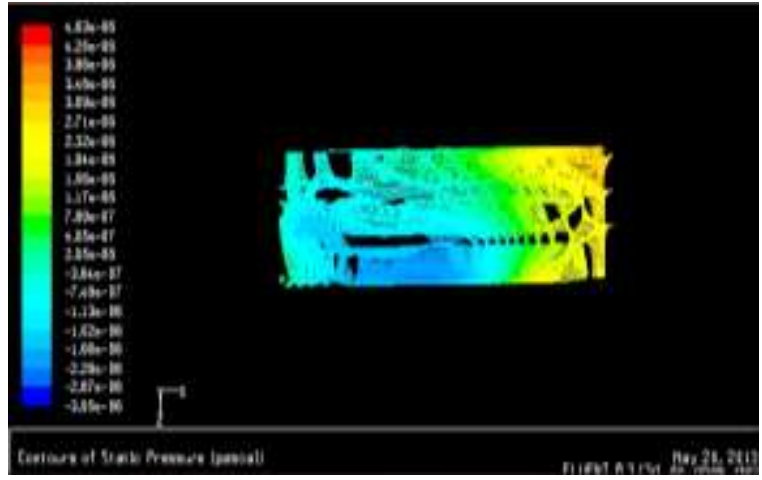

Fig. 4.5 Contours of Static Pressure Profile

As shown in the above Fig.4.5, the observed pressure was less near sampling point 1 . Due to this pressure drop the concentration of pollutants is more near sampling point 1 .

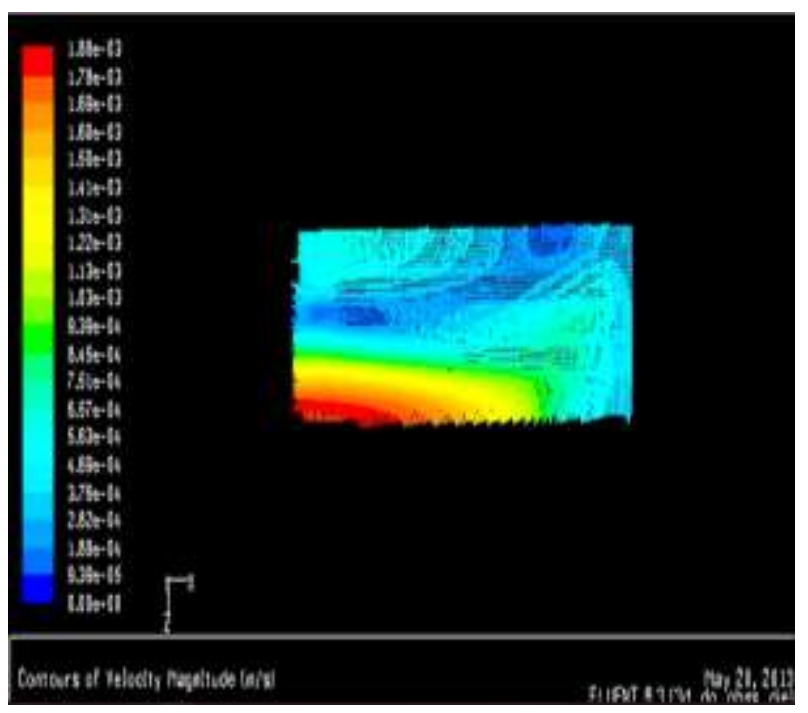

Fig. 4.6 Contours of Velocity Magnitude Profile

As shown in the above Fig 4.6, the velocity profile is more towards the sampling point 1 than near sampling point 2 . Due to pressure drop there was increase in velocity towards sampling point 1 and hence pollutants concentration was more near the sampling point 1 than compared with the sampling point 2 .

\section{CONCLUSION}

From this work it can be concluded as

- The concentration of pollutants such as $\mathrm{SPM}, \mathrm{SO}_{2}$ and $\mathrm{NO}_{2}$ was found to be more near sampling point 1 than compared to sampling point 2 due to more vehicular count and pressure drop near sampling point 1

- The concentration of SPM was more i.e., 1581.6 $\mu \mathrm{g} / \mathrm{m}^{3}$ near sampling point 1 and it was less near sampling point 2 i.e., $706.45 \mu \mathrm{g} / \mathrm{m}^{3}$ due to more accumulation of dust 
- As there was more vehicular movement, the concentration of $\mathrm{NO}_{2}$ was more near sampling point 1 i.e., $2020.23 \mu \mathrm{g} / \mathrm{m}^{3}$ than compared to sampling point 2 i.e., $394.7 \mu \mathrm{g} / \mathrm{m}^{3}$

- In the case of $\mathrm{SO}_{2}$ the concentration was negligible in both the sampling points because the exhaust emission from vehicles does not contain more concentration of $\mathrm{SO}_{2}$

- When modeled using FLUENT, the pressure drop was observed near the first sampling point and hence the movement of pollutant towards the pressure drop was more. This results in the more accumulation of the pollutants at that particular sampling point.

\section{REFERENCES}

[1] A. Galani Neofytou, A. Venetsanos, J. Bartzis and S. Neville, 2009. "Prediction and Study of Pollutant Dispersion in A Street canyon in London Using Computational Fluid Dynamics Techniques". Global NEST Journal, Vol. 11, pp 434- 439

[2] Alan J. Cimorelli, Steven G. Perry, Akula Venkatram, Jeffrey C. Weil, Robert J. Paine, Robert B. Wilson, Russell F. Lee, Warren D. Peters and Roger W. Brode 2004. "AERMOD: A Dispersion Model for Industrial Source Applications. Part I: General Model Formulation and Boundary Layer Characterization. Journal Of Applied Meteorology, Vol. 44, pp 682-693

[3] Alexander Baklanov, 2000. "Application of CFD Methods for Modelling in Air Pollution Problems: Possibilities and Gaps". Journal Environmental modeling and assessment, Vol. 65, pp 189-190

[4] Brian P. Leaderer and Theodore R. Holford, 2010. "Modeling effects of traffic and landscape characteristics on ambient nitrogen dioxide levels in Connecticut". Atmospheric Environment, Vol. 44, pp 5156-5164

[5] Cheng-Hsin Chang, Robert N. Meroney, 2003. "Concentration and flow distributions in urban street canyons: wind tunnel and computational data". Journal of Wind Engineering and Industrial Aerodynamics, Vol. 91, pp 1141-1154

[6] D. Mumovic, J.M. Crowther and Z. Stevanovic, 2005. "Integrated air quality modelling for a designated air quality management area in Glasgow". Building and Environment.

[7] Fabio Murena, 2012. "Monitoring and modelling carbon monoxide concentrations in a deep street canyon: application of a two - box model". Atmospheric Pollution Research, Vol. 3, pp 311-316

[8] G. Wang a, F. H. M. van den Bosch and M. Kuffer, 2008. "Modelling Urban Traffic Air Pollution Dispersion"

[9] Gustavo Olivaresa, Christer Johanssona, Johan Stro"ma, Hans-Christen Hansson, 2007. "The role of ambient temperature for particle number concentration in a street canyon". Atmospheric Environment, Vol. 41, pp 21452155

[10] J. Garcia, R. Cerdeira, N. Tavares and L. M. R. Coelho, 2011. "Studying the Effect of Street Geometry in Particle Concentration", 14th Conference on Harmonisation within Atmospheric Dispersion Modelling for

Regulatory Purposes, pp579-583

[11] J.D. McAlpine and Michael Ruby, 2004. "Using CFD to Study Air Quality in Urban Microenvironments". Environmental science and Environmental computing, Vol. 2, pp1-31

[12] Jong-Jin Baik, Jae-Jin Kim and Harindra J. S. Fernando, 2003. "A CFD Model for Simulating Urban Flow and Dispersion”. Journal of Applied Meteorology, Vol. 42, pp 1636-1648

[13] Minjoong J. Kim, Rokjin J. Park and Jae-Jin Kim, 2012. "Urban air quality modeling with full $\mathrm{O}_{3}-\mathrm{NO}_{\mathrm{x}}-\mathrm{VOC}$ chemistry: Implications for $\mathrm{O}_{3}$ and PM air quality in a street canyon". Atmospheric Environment, Vol. 47, pp 330-340

[14] P. Goussea, B. Blocken, T. Stathopoulos, G.J.F. Van Heijst, 2011. "CFD simulation of near-field pollutant dispersion on a high resolution grid: a case study by LES and RANS for a building group in downtown Montreal" Atmospheric Environment, Vol. 45, pp 428-438

[15]Parham A. Mirzaei and Jan Carmeliet,2012.

"Dynamical Modeling of Stochastic Wind Flow in Street Canyons", International High Performance Buildings Conference at Purdue.

[16]S. Di Sabatino, R. Buccolieri, B. Pulvirenti and R. E. Britter, 2007. "Flow and Pollutant Dispersion in Street Canyons using FLUENT and ADMS-Urban", Environment Model assess, Vol. 13, pp 369-381

[17] S. M. Salim, K. C. Ong and S. C. Cheah, 2011 "Comparision of RANS, URANS and LES in the prediction of Airflow and Pollutant Dispersion". Proceedings of the World Congress on Engineering and Computer Science, Vol. 2

[18] Sathe Yogesh V, 2012. "Air Quality Modeling in Street Canyons of Kolhapur City, Maharashtra, India". Universal Journal of Environmental Research and Technology, Vol. 2, pp 97-105

[19] U. W. Tang, Z.S.Wang, 2008."Fragmentation of Urban Forms and the Environmental Consequences: Results from a High-Spatial Resolution Model System". SPIE, Vol. 7, 144, pp 1-9

[20] U.W. Tang and Z.S. Wang, 2007."Influences of urban forms on traffic-induced noise and air pollution: Results from a modelling system". Environmental Modelling \& Software, pp 1-15

[21] Xian-Xiang Li, Dennis Y. C. Leung, Chun-Ho Liu and K. M. Lam, 2007. "Physical Modeling of Flow Field inside Urban Street Canyons". Journal of Applied Meteorology and Climatology, Vol. 47, pp 2058- 2067

[22] Ratnesh Trivedi, M. K. Chakraborthy and B. K. Tewary, 2009. "Dust Dispersion Modelling using fugitive dust model at an open cast coal project of Western Coal Field Limited, India". Journal of scientific and research, Vol. 68, pp 71-78 